\title{
Exploring deliberate practice in medicine: how do physicians learn in the workplace?
}

\author{
Margje W. J. van de Wiel • Piet Van den Bossche • \\ Sandra Janssen $\cdot$ Helen Jossberger
}

Received: 16 March 2010/ Accepted: 23 August 2010/Published online: 18 September 2010

(C) The Author(s) 2010. This article is published with open access at Springerlink.com

\begin{abstract}
Medical professionals need to keep on learning as part of their everyday work to deliver high-quality health care. Although the importance of physicians' learning is widely recognized, few studies have investigated how they learn in the workplace. Based on insights from deliberate practice research, this study examined the activities physicians engage in during their work that might further their professional development. As deliberate practice requires a focused effort to improve performance, the study also examined the goals underlying this behaviour. Semi-structured interviews were conducted with 50 internal medicine physicians: 19 residents, 18 internists working at a university hospital, and 13 working at a non-university hospital. The results showed that learning in medical practice was very much embedded in clinical work. Most relevant learning activities were directly related to patient care rather than motivated by competence improvement goals. Advice and feedback were sought when necessary to provide this care. Performance standards were tied to patients' conditions. The patients encountered and the discussions with colleagues about patients were valued most for professional development, while teaching and updating activities were also valued in this respect. In conclusion, physicians' learning is largely guided by practical experience rather than deliberately sought. When
\end{abstract}

\author{
M. W. J. van de Wiel ( $\square)$ \\ Department of Work and Social Psychology, Faculty of Psychology and Neuroscience, \\ Maastricht University, P.O. Box 616, 6200 MD Maastricht, The Netherlands \\ e-mail: m.vandewiel@maastrichtuniversity.nl \\ P. Van den Bossche \\ Department of Educational Research and Development, Maastricht University, \\ Maastricht, The Netherlands \\ P. Van den Bossche \\ Institute for Education and Information Sciences, University of Antwerp, Antwerp, Belgium
}

S. Janssen

Ruud de Moor Centre, Open University of the Netherlands, Heerlen, The Netherlands

H. Jossberger

Centre for Learning Sciences and Technologies, Open University of the Netherlands, Heerlen, The Netherlands 
professionals interact in diagnosing and treating patients to achieve high-quality care, their experiences contribute to expertise development. However, much could be gained from managing learning opportunities more explicitly. We offer suggestions for increasing the focus on learning in medical practice and further research.

Keywords Deliberate practice - Medical expertise $\cdot$ Physicians $\cdot$ Residents Self-regulated learning · Workplace learning

\section{Introduction}

Good professional conduct in medicine, as reflected in the requirements of good medical practice (General Medical Council 2009), the principles of medical ethics (American Medical Association 2009), and the oath taken by medical graduates (e.g., Royal Dutch Medical Association (KNMG) 2003), includes the responsibility of physicians to continue learning and keep their knowledge and skills up to date in order to provide competent patient care. To maintain professional expertise, physicians need to incorporate new developments in their field as regards the diagnosis and treatment of patients and learn from their experiences in clinical practice. It has been argued that this requires deliberate practice, i.e., a focused effort to develop performance aspects that need improvement (Ericsson 2004). However, it is not obvious whether physicians invest time in deliberate practice when patient care demands their full attention. The present study explored how physicians learn in, from and for their daily work and how deliberate this learning process is.

\section{Deliberate practice and workplace learning}

Deliberate practice has mostly been studied in the domains of music, sports and chess (Ericsson 2006). Based on specific goals to improve performance, experts repetitively practise tasks that allow them to refine their knowledge and skills. They are usually supported by trainers and coaches who design structured practice activities aimed at performance improvement and provide informative feedback, and gradually learn to monitor, control and evaluate their performance, enabling high-quality independent practice. In introducing deliberate practice, Ericsson et al. (1993) argued that deliberate practice might be hard to realise in work settings. At work, people have to give their best performance in job-related tasks in a limited time-frame and usually cannot give much attention to finding and trying out new methods and procedures to accomplish these tasks. Although people might learn from the results they obtain and from feedback, the conditions for learning at work are regarded as far from optimal. Conscious efforts to counteract automaticity and to gain high-level control of performance are deemed necessary to go beyond routine behaviour and achieve real expertise (Ericsson 2004, 2006).

A review of the acquisition and maintenance of expert performance in medicine (Ericsson 2004) has shown that specialised training and immediate informative feedback provide the best conditions for performance improvement. Repetitive practice with representative tasks was found to be realised more often in perceptual diagnosis of abnormality (e.g., library of X-rays) and surgery (e.g., simulators) than in the diagnosis of patients. The lack of clear performance standards was identified as a major problem for building professional expertise in medicine. Work experiences that are thought to 
contribute to diagnostic reasoning include specialisation by seeing more patients with similar diseases, accurate feedback by using sophisticated diagnostic equipment, interaction with knowledgeable colleagues, involvement in teaching and supervision, and contribution to active research programmes. However, these assumptions have not been tested yet.

Only a few studies have examined deliberate practice in the workplace (Dunn and Shriner 1999; Sonnentag and Kleine 2000; Van de Wiel et al. 2004), relating to the fields of education, insurance and organisational consultancy. These studies looked for activities that are performed with the aim of learning or improving professional competence. The work-related activities identified as deliberate practice in these work settings included preparation, mental simulation, asking for feedback or advice, evaluation, reflection and updating activities. These activities are similar to key elements of self-regulated learning (Van de Wiel et al. 2004; Zimmerman 2006).

Self-regulation refers to self-generated thoughts, feelings and actions that are strategically planned and adapted to the attainment of personal goals (Zimmerman 2000, 2006). The process entails three interrelated phases, viz. before, during and after task performance, and relates to domain and personal knowledge. In the forethought phase, goals are set and strategies are planned. These may be adjusted in the performance phase, based on careful monitoring of task progress, the self and the context. For example, one could seek help when this is necessary to accomplish a task. In the reflection phase, the outcomes are evaluated and reflected upon to generate useful information for subsequent performance. When the explicit goal is to learn from task performance, learning is proactively planned and not merely reactively generated (Pintrich 2000). This focus on competence improvement is known as a mastery goal orientation (Pintrich 2000). In line with deliberate practice theory, a supportive environment, in which (regulatory) skills are taught, modelled, practised and evaluated, is regarded as crucial to achieve high-level performance (Ericsson 2006; Van de Wiel et al. 2004; Zimmerman 2000).

It can be concluded that from the perspective of deliberate practice and self-regulated learning, the processes of reflecting on work experiences and deliberately looking for situations and tasks that may contribute to professional development can be identified as key principles for workplace learning (Van de Wiel et al. 2004). According to the typology of non-formal learning proposed by Eraut (2000), these activities obviously go beyond the unintentional and unconscious implicit learning from experience, but may encompass the reactive learning that is triggered by specific events, and definitely coincides with the highest intentional level of deliberative learning in which learning is planned.

\section{Learning in medical practice}

The reflective and self-directed nature of learning in practice is also widely recognised in the context of medical education as an important aspect of the professional development of students, residents and practitioners (Duffy 2008; Epstein et al. 2008; Holmboe et al. 2005; Mann et al. 2009; Wyatt and Sullivan 2005). As life-long learners, physicians need these skills to solve problems they encounter when diagnosing and treating patients and to remedy weaknesses in their knowledge and skills as part of continuing medical education (Duffy 2008; Slotnick 1996). This allows them to expand their expertise deliberately, and go beyond the mere accumulation of experiences (Guest et al. 2001; Mylopoulos and Regehr 2007). This is stressed by deliberate practice theory as applied to medicine 
(Ericsson 2004), and has been addressed as such by several authors (Guest et al. 2001; Mamede and Schmidt 2004; Norman et al. 2006). Self-assessment of performance and learning needs is argued to play a critical role in advancing knowledge-based reasoning in clinical practice (Epstein et al. 2008; Eva and Regehr 2005, 2008).

The literature on physicians' learning in clinical practice is dominated by theoretical work, analysing and prescribing what physicians should do, rather than describing what they actually do. Only a few empirical studies have focused on the way experienced physicians learn in practice (Mamede and Schmidt 2004; Sargeant et al. 2006; Slotnick 1999). Some more research is available on learning by residents (Hoffman and Donaldson 2004; Stok-Koch et al. 2007; Teunissen et al. 2007), who are trained while doing their job, and medical students who participate as clerks in clinical work (Deketelaere et al. 2006; Dornan et al. 2007; Sheehan et al. 2005). These studies showed that learning in medical practice is very much embedded in work activities. Residents and physicians indicated that they learned from the patient cases they encountered and their cooperation with colleagues and other specialists in daily work routines (Hoffman and Donaldson 2004; Sargeant et al. 2006; Slotnick 1999; Stok-Koch et al. 2007; Teunissen et al. 2007). Slotnick (1999) found that learning was triggered by specific problems in patient care that needed immediate action and by general problems relating to gaps in knowledge and skills. The specific problems were solved by consulting directly available sources, such as colleagues and the literature, whereas the general problems were dealt with more deliberately by planning courses and independent study. This difference between on-the-spot learning and planned learning by goal-setting over time was also found by Sargeant et al. (2006) in a sample of highly competent family physicians. Issues that were found to influence learning were the type of patient cases dealt with, the tension between work load and the time available for teaching and learning, and the learning climate (Hoffman and Donaldson 2004; Stok-Koch et al. 2007).

The present study builds on these findings by questioning if and how physicians exploit learning opportunities in their daily work. In contrast to the previous studies, we reversed the starting point of examination by focusing on relevant work-related activities instead of directly asking for learning experiences and the factors that influence them. This method is based on deliberate practice research (Ericsson 2004, 2006), which investigates the involvement in relevant practice activities, including the underlying goals of this behaviour (Sonnentag and Kleine 2000; Van de Wiel et al. 2004). It has also been advocated for research into workplace learning, as it focuses on normal work situations and allows information on implicit learning to be collected (Eraut 2004). The present study therefore examined the activities physicians engage in during their work that might contribute to professional development, and the extent to which a deliberate effort for learning was made. We focused on the core competence of diagnosing and treating patients (Frank 2005 ) as the representative task. Because we wanted to study individual practices in detail, we used the method of semi-structured interviews. We interviewed both residents and experienced physicians in internal medicine to be able to identify differences in practice patterns and underlying goals.

The activities we looked at to determine whether respondents deliberately engaged in learning were derived from the theories of deliberate practice and self-regulated learning, and informed by research on workplace learning in medicine. Potential learning opportunities in practice arise when problems are experienced in diagnosing and treating patients. This may induce reflection and problem solving (Ericsson 2004; Slotnick 1999). Consultation with knowledgeable colleagues is a powerful strategy to solve these problems (Eraut 2007; Ericsson 2004; Van de Wiel et al. 2004). In these consultations, 
differences of opinion concerning patient care may also trigger further thinking and lead to substantiated changes in approach (Van den Bossche et al. 2006). Explaining things to others, as is done in teaching and supervision, also contributes to learning as it requires expressing knowledge and argumentation, and thus elaboration (Eraut 2007; Ericsson 2004; Van de Wiel et al. 2004). The role of feedback in learning is crucial to deliberate practice, as are the criteria set for performance (Ericsson 2004; Zimmerman 2006). Residents get feedback during supervision, but do physicians recognise and seek feedback in other ways, and what criteria do they use to evaluate their performance? Finally, we investigated involvement in specific updating activities, including compulsory continuing medical education and participation in research (Ericsson 2004; Van de Wiel et al. 2004).

\section{Methods}

Context and participants

The study was conducted in the Netherlands among 50 physicians working in internal medicine. Participants were 19 residents, 18 internists working at a university medical centre, and 13 internists working at a non-university hospital. Residents have a 6-year training programme in which they practise internal medicine under supervision and usually specialise further in their final year. Most of the experienced internists practised general internal medicine as well as a particular subspecialty, such as clinical pharmacology, endocrinology, geriatrics, haematology, oncology, intensive care, nephrology, rheumatology or vascular medicine. Further descriptive information on the 3 groups is provided in Table 1.

\section{Interviews}

We conducted semi-structured interviews with internists on the activities they engaged in during their work that might contribute to professional development. This allowed us to examine individual practices in detail, while the open questions ensured spontaneous reactions (Emans 2004). The questions were developed from the theories of deliberate practice (Ericsson 2004, 2006) and self-regulated learning (Zimmerman 2000, 2006) and built upon earlier work (Van de Wiel et al. 2004). They were attuned to the medical

Table 1 Description of sample characteristics

\begin{tabular}{|c|c|c|c|c|c|c|}
\hline & \multicolumn{2}{|c|}{$\begin{array}{l}\text { Residents } N=19 \\
(11 \mathrm{M}, 8 \mathrm{~F})^{\mathrm{a}}\end{array}$} & \multicolumn{2}{|c|}{$\begin{array}{l}\text { Internists at non-university } \\
\text { hospitals } N=13(11 \mathrm{M}, 2 \mathrm{~F})\end{array}$} & \multicolumn{2}{|c|}{$\begin{array}{l}\text { Internists at university } \\
\text { hospitals } N=18(15 \mathrm{M}, 3 \mathrm{~F})\end{array}$} \\
\hline & $M$ & $S D$ & $M$ & $S D$ & $M$ & $S D$ \\
\hline Age & $32.4 *$ & 4.7 & 46.4 & 6.9 & 44.2 & 9.2 \\
\hline Years of work experience & $4.9^{*}$ & 2.3 & 19.0 & 6.7 & 18.0 & 8.8 \\
\hline Working hours a week & 50.7 & 4.9 & 54.7 & 12.2 & 55.4 & 8.6 \\
\hline Number of patients a week & 38.3 & 20.2 & $89.4 *$ & 27.7 & 33.2 & 15.9 \\
\hline
\end{tabular}

* Group differs significantly from other groups, $p<0.01$

${ }^{a} M$ male, $F$ female 
situation, based on the above discussion of workplace learning research in medicine. At recruitment, participants were told that the interview was about professional development. However, only the last question was framed from this perspective, whereas all others focused on concrete situations and behaviours in the workplace, emphasising the core competence of diagnosis and treatment as the representative task.

The interview started with questions about work experience, weekly work-related activities, and the goals participants aspired to in their work. It further focused on the kind of diagnostic and treatment problems they encountered and how they dealt with them, in what situations they asked for advice, to what extent they felt comfortable in doing so, how they handled differences of opinion, and how they were involved in explaining things to others. Subsequently, it focused on receiving, searching for and utilising feedback, and how they evaluated the quality of their decisions and actions. Finally, they were asked what activities they thought contributed most to professional development, including continuing medical education and participation in research. In exploring the different activities with the interviewees, explicit attention was given to the goals underlying their involvement in the activities.

\section{Procedure}

Internists in several hospitals in the south of the Netherlands were first approached by the head of the Department of Internal Medicine at Maastricht University Medical Centre and subsequently contacted by the interviewers (SJ and HJ). The final response rates were 51, 20 and $58 \%$ for the residents (two hospitals), internists working at non-university hospitals (six hospitals) and internists working at university hospitals (three hospitals), respectively. The main reason for not participating was being too busy. The interviews were administered individually at the internists' offices. They were followed by two questionnaires that are not reported on here. The whole procedure took about $1.5 \mathrm{~h}$. In accordance with the Declaration of Helsinki, participants signed an informed consent form and data were treated anonymously.

\section{Analyses}

The interviews were transcribed verbatim. Content analysis was used to categorise participants' answers. Analysis proceeded in an iterative process in which two coders (SJ and HJ) consecutively categorised sets of data. These categorisations were reviewed and critically discussed by all authors. The analysis started from the main themes and activities that were addressed by the questions. Answers were grouped on the basis of these themes and further categorised into subthemes that emerged from the data. The intention was to summarise what had been said by the participants and to indicate to what extent they concurred on a subtheme (Neuendorf 2002). We also identified the more exceptional responses.

\section{Results}

The findings are summarised below according to the main themes of physicians' workplace learning as theoretically identified and addressed by the questions (see Table 2 for illustrative quotes). First, we briefly describe participants' work activities. 
Work activities

Participants filled in a week schedule to characterise their daily activities. Internists working in non-university hospitals spent considerably more time in the outpatient clinic than the other two groups, while internists working in university hospitals spent more time on research, teaching and supervision. Residents were primarily responsible for the wards and accordingly spent more hours caring for hospitalised patients. As part of their training, they spent more time on education. All participants were regularly involved in patient review meetings and administrative work. Many experienced internists had management tasks and/or participated in committees.

\section{Goals}

Providing high-quality patient care was the main professional goal for all participants. For some this also meant being a good and caring person, or working efficiently and accurately. Half of the experienced internists said they aimed to be good educators. Residents, on the other hand, had more explicit learning goals. Many internists working in university hospitals also wanted to contribute through research. Almost half of the participants said they sought pleasure or satisfaction in their work.

Problems and problem solving

Although some participants said they did not encounter problems in diagnosing and treating patients, most participants experienced medical and/or practical problems. Problems of diagnosis arose when patient data could not be unequivocally interpreted, especially when the patient's complaints were not substantiated by diagnostic tests, the patient had a rare or complex, multi-faceted disease, or the internist lacked specific knowledge. Choosing the right diagnostic tools and figuring out the best therapy for a patient could be problematic too, with quality of life issues also coming into play. The diagnostic and therapeutic process was complicated by demanding and non-cooperative patients. In practical terms, participants said they were hampered by logistic problems, such as arranging and waiting for test results and other specialists involved, and a shortage of facilities.

Medical problems were solved by thinking about alternatives, mostly by searching guidelines and the literature and asking colleagues for advice. Difficult cases could be discussed in daily or special patient review meetings. Careful communication with patients and their family was needed to handle certain difficulties. Organisational problems were hard to overcome and required persistence. More than half of the participants said they learned from problems.

\section{Asking colleagues for advice}

While most experienced internists said they asked for advice 1-3 times a week, many residents did so every day. They consulted colleagues when they had insufficient knowledge to help a patient, and to discuss a case when they were uncertain and wanted to be reassured. Learning was incidental to the task. They knew whom to approach for a particular problem and the main reason to ask a particular colleague was his/her expertise. When more experts were available, personal preferences in terms of accessibility and working style were decisive. Residents naturally referred to their supervisors. All felt at 
Table 2 Quotes from the interviews illustrating the themes

\section{Goals}

Providing the right medical care, that is the main thing. That means being patient-friendly, so no unnecessary examinations, partly in view of costs, and trying to be as clear as possible in communication. On a purely personal level, I want to be as good as I can, in terms of knowledge. You need to get better all the time, so you need to study, even in weekends. (R9) ${ }^{\mathrm{a}}$

Optimum patient care is paramount, and then to get some satisfaction, a career, and grow in your profession, yes, being proud of what you achieve. (R41)

Problems and problem solving

Sometimes it's hard to establish a diagnosis from various complaints and lab test results. ... I look on the Internet, Pubmed, we have Uptodate, a very useful program. But I'm not afraid to ask my superiors, I think they're all easy to communicate with. And the nurses are very open to communication too. I think you can learn a lot from them too. (R19)

I see many routine cases. Occasionally you have to look things up. Occasionally it's good to test your own opinion against those of others. That's what the Friday afternoon patient review meetings are for, ... our strength is that we're a team; by talking to each other, we improve our level. (UI35)

Asking colleagues for advice

When I'm uncertain, or a patient wants more certainty. ... I've learned there's a lot I don't know, and that if you don't know something, you should ask others or refer the patient. (NUI14)

There are a few specialists who are a bit grumpy and curt, who will give me an answer that I don't learn much from. Who just tell me to solve the problem in a particular way, without asking me questions or explaining why. (R28)

You ask the others informally at patient review meetings: What would you do? And at least once a week I ask a colleague: I intend to do this, would you agree? So it's coordination, ensuring the patient does get the same information from all doctors. (UI32)

\section{Differences of opinion}

You exchange arguments, views and considerations, and there are usually more options, so you discuss. ... The decision has to be made by the one who's ultimately responsible for the patient. (UI2)

If I disagree with the advice I get, I won't go along with it, or I'll ask a second or third opinion to see if I get the same advice. If I do, I have to reconsider, ... I have a look at the literature. So when in doubt you have to look further afield. (R31)

We have them every day at the intensive care. We discuss things openly and try to reach consensus. Sometimes I have arguments that convince my colleague, sometimes it's the other way around. (NUI36).

\section{Explanations}

I think you also learn things yourself while explaining, as you may discover gaps. (R24)

Residents, colleagues and of course nurses, it's very important that they know why they do something, so things will improve. (UI46)

Feedback

Fortunately, patients are so articulate now that they spontaneously say what they like and don't like; they communicate without restraint. You don't get that so much in the rest of your work. (UI8)

There's nobody beside you in the consultation room to see how you're doing, so you get little feedback on the way you function. (NUI44)

\section{Evaluation of diagnosis and treatment}

The patient, and of course you can look back at the path you've taken. When you're dictating a letter, that's one of these moments where you think that was good, or, perhaps I could have taken a different approach here, or, I shouldn't have done that. (R20)

Sometimes you get feedback from a GP, who lets you know how the patient fared later and whether they were satisfied with the outcome. (UI23)

That's very difficult to assess. ... [in the case of pneumonia] you can say the antibiotic worked well, but the patient might also have got better without antibiotics. (NUI50) 
Table 2 continued

Professional development

You improve your knowledge and expertise in contacts with residents, that's where you delve deeper, get feedback and get questions you have to try and answer. (UI4)

I especially learn from the meetings with colleagues, the handover meeting, the ward round; and you learn a lot from teaching. (NUI22)

I find patient contacts most important. Each time there's a new problem to think about, at the outpatient clinic or on the ward, and you adjust your ideas during ward rounds. (R34)

Contribution to knowledge development

By engaging in research you learn how to investigate things and to evaluate the literature. It gives me a wider view of the field. (R13)

I include patients in research and hope we find out things and can treat patients more effectively. (NUI43)

If you work in a university hospital, you'll have to engage in research. That's more interesting than just doing outpatients of course, a certain intellectual development. (UI47)

${ }^{a}$ Indication of participants by group and number; R refers to residents, NUI to internists working at nonuniversity hospitals and UI to internists working at university hospitals

ease about consulting colleagues, as it was common practice and everyone was approachable. Almost half of the participants spontaneously said it was no problem to show what you do not know. If particular colleagues were not approached, this was usually because of doubt about their competence, and rarely for personal reasons.

\section{Differences of opinion}

All participants indicated they sometimes had differences of opinion, as there was often not one perfect solution to a problem. In these situations, they usually exchanged arguments to arrive at a common point of view. When they became convinced the other approach was better they would use it. But if they could not agree, the decision would rest with the person who was ultimately responsible, and residents would go along with their supervisor. In some cases, they consulted the literature or a third party (colleague, patient and family, general practitioner). Only a few participants mentioned that they learned from differences of opinion.

\section{Explanations}

Providing explanations was a part of participants' everyday work. They informed patients about illness and treatment, and colleagues and nurses about their approach. This was often used to create commitment and promote cooperation. Furthermore, they explained things while teaching students, clerks and residents, when giving presentations, and when consulted by colleagues. Almost half said they enjoyed explaining. Some mentioned learning as a by-product of explaining.

\section{Feedback}

Although we asked how participants received feedback when diagnosing and treating patients, only some mentioned the results of diagnostic tests or the patient's condition. Most participants associated feedback with comments from others. Comments on medical 
issues came from other specialists, paramedics and nurses who knew the patient, usually when discussing the case in regular patient review meetings or in consultations. Residents received regular feedback from their supervisors. Feedback on the way they function came from patients and sometimes from residents, students, and nurses. Quite a few said they received little feedback, and some did not mind, but most made an effort to get feedback when they thought they needed it. Several sought feedback to improve their competences. Almost all said they used feedback to adjust their approach.

Evaluation of diagnosis and treatment

When asked how they assessed whether they diagnosed or treated a patient correctly, most referred to the course of disease, the patients' condition and satisfaction, and test results. Some reflected afterwards on the steps taken or checked what others thought about the patient. Quite a few said they found this a difficult or interesting question as they usually did not think much about it. Several participants stressed that it is often hard to assess.

\section{Professional development}

Among their regular duties, participants found contacts with patients and patient review meetings most important for their professional development. For residents, this included supervision. For experienced internists, teaching came in third place, while for residents training and independent study came third. Besides these regular tasks they found continuing medical education important to keep up-to-date and develop further. This comprised attending conferences, presentation sessions, refresher courses, seminars, the Dutch internists' conference, and independent studies. Taking an active role in presentations was regarded as valuable, as was research. Most spent more hours on continuing medical education than required for their (re)registration. It was valued not only for its content, but also for social contacts and networking.

Contribution to knowledge development

Finally we asked whether the respondents themselves contributed to the advancement of knowledge in internal medicine, as this is considered the ultimate step in expertise development (Ericsson 2004, 2006). Most internists at university hospitals contributed through research, and this was also true for some internists at non-university hospitals and some residents. Quite a few participants emphasised their role in educating others. A few wrote guidelines. Most enjoyed these tasks, were curious to learn, and wanted to further the development of their profession. A few mentioned career reasons.

\section{Discussion}

The present study used a deliberate practice (Ericsson 2006) and self-regulated learning perspective (Zimmerman 2000, 2006) to examine physicians' involvement in work-related activities that may further their professional development. In line with the few other studies on physicians' workplace learning (Hoffman and Donaldson 2004; Sargeant et al. 2006; Slotnick 1999; Stok-Koch et al. 2007; Teunissen et al. 2007), our study showed that in this sample of internists, learning in the workplace was very much embedded in clinical work. 
Our investigation into whether physicians deliberately engage in work activities to foster learning showed that patient care was their first concern. The physicians checked guidelines and consulted knowledgeable colleagues when they felt this was necessary to help their patients. They indicated that they learned most from the patient cases they encountered and the discussions about patients. Learning goals were more clearly defined among residents, while experienced internists emphasised their role as educators and supervisors. In sum, the activities contributing to learning in medical practice seem inherent to the job of providing high-quality patient care, rather than motivated by competence improvement goals.

These results are disappointing from a deliberate practice and self-regulated learning point of view. Practical experience guided development rather implicitly and reactively by triggering reflections and problem solving. Performance standards were tied to patients' conditions and not always considered straightforward. Accurate monitoring of uncertainty in medical decision making and accurate assessment of one's own knowledge and skills is required to recognise and follow up on potential problems. This means that it is the quality of the assessment of one's own performance which largely determines whether advice or feedback is sought. Once again, this points to the crucial role of self-assessment practices to improve clinical care and learning (Epstein et al. 2008; Eva and Regehr 2005, 2008), and the necessity to discuss performance standards and check up on them (Davis 2009; Ericsson 2004; Sargeant et al. 2006). Although these results might be unsurprising to practicing physicians, they are quite startling if one realises that doctors, who bear a great responsibility for patients' wellbeing, do not extensively engage in the type of deliberate practice that professionals in more competitive domains would do to stay at the top of their games (Ericsson 2004, 2006). Our study clearly suggests that learning opportunities at clinics could be better recognised and more deliberately exploited.

The good news is that learning, teaching and practising medicine are so intertwined that the aim of high-quality patient care allows everyday experiences to contribute to the development of medical expertise (Norman et al. 2006). Moreover, patient care is a common endeavour in which professionals from various disciplines share responsibilities (Bleakley 2006). If each professional actively contributes, by carefully considering patient information and questioning previous management and conclusions, this enables a controlled and self-corrective group practice in which relevant decisions are discussed. The eagerness of physicians to discuss complex cases may be exploited by organisations to promote learning and improve patient safety. Cases in the outpatient clinic might also be examined to generate feedback by exchanging experiences and ideas.

The other good news is that the residents and internists in this study did not hesitate to ask others for advice, felt comfortable about doing so, and knew how to find the experts on a topic. Such a safe working and learning climate is a prerequisite to improved competence and performance (Edmondson 1999). Teaching and updating activities were also valued for professional development.

From a theoretical perspective, this study on the activities physicians may engage into promote their competence in diagnosing and treating patients confirms that deliberate practice is hardly realised during work (Ericsson et al. 1993). In Eraut's typology of nonformal learning (Eraut 2000), physicians' learning in medical practice can be characterised as implicit and reactive rather than deliberative. In the views of both Ericsson (2004) and Eraut (2000) involvement in well-considered decision making and problem solving clearly represents performance control at a conscious level that may contribute to competence improvement. However, this behaviour was mostly instigated for the patients' sake. Apart from participation in continuous medical education, learning was usually not planned, and 
certainly not in the way experts in more competitive domains do to fine-tune their performance. As the training of medical specialists is largely on-the-job, it is pre-eminently representative of their domain, but lacks opportunities for premeditated repetitive practice. Further specialisation will increase the number of cases seen and the number of procedures performed, leading to relatively more practice in routine cases than in the rare and complex cases for which expert thinking and action are required. Specifically designed practice activities with a highly repetitive character might be feasible for some well-defined tasks, such as perceptual diagnosis and surgical skills, provided clear performance standards are available to enable informative feedback, and provided time and resources are set aside (Ericsson 2004). The challenge for improving diagnosis and treatment is to increase experience with interesting cases that afford more in-depth knowledge. A well-developed knowledge base that allows control by direct retrieval of relevant alternatives and enables reasoning about a patient's problem in case of uncertainty is a prerequisite for high-quality patient care (Ericsson 2004; Norman et al. 2006).

A limitation of the present study was a possible selection bias. Although we interviewed a large sample of 50 internists, with various levels of experience and working in different specialties and hospitals, due to a low response rate our participants may have been those who were particularly motivated for learning. This, however, rather strengthens our conclusion that more deliberate effort for learning is needed. Another limitation is that we only gathered reports from the physicians themselves and did not collect more objective information on their behaviours from observations or documents. However, we did endeavour to create an open, informal atmosphere during the interviews. The questions focusing on concrete situations and behaviours in the workplace elicited spontaneous answers that yielded insights into the way participants engaged in work-related learning activities. The answers reflected the thoughts that first came into the respondents' minds in this particular interview setting and were elaborated when the respondents were prompted, to ensure that comparable data were obtained.

Our interview approach, focusing on concrete work experiences, validated and extended the findings of previous studies that more broadly examined participants' learning experiences in the workplace (Hoffman and Donaldson 2004; Sargeant et al. 2006; Slotnick 1999; Stok-Koch et al. 2007; Teunissen et al. 2007), across specialties (e.g., internal medicine, psychiatry, gynaecology, family medicine, nursing home medicine), work settings and cultures. Although these studies on physicians' learning mostly used interviews, and research needs to be extended with other methods such as observations, the available data suggest that clinical performance in various disciplines may benefit from more deliberate efforts to learn. Moreover, our results agree with those of research in other professional domains (Eraut 2004) showing that much learning in the workplace is informal and a by-product of work-based goals rather than deliberately pursued. The following recommendations for improving learning in the workplace may therefore be more generally applicable.

Medical practice provides abundant meaningful learning opportunities that could be better utilised by facilitating the conditions for knowledge and skill development. The first priority is to sustain a group climate for learning by encouraging critical thinking, questioning in case of uncertainties, and checking mutual understanding (Kisiel et al. 2010; Sutkin et al. 2008; Van den Bossche et al. 2006). Management can contribute by initiating work procedures that facilitate these knowledge exchanges, and by identifying recurrent organisational problems in order to improve practices and free up precious time for learning. Natural moments for reflection on patient cases, such as handovers and handoffs, could be used to review the course of disease and patient care. Individual practices, for 
example in the outpatient clinic, can be scrutinized for cases that are valuable to share. The link between learning needs and continuing medical education may be strengthened to enable deliberate practice and improve transfer to the workplace.

This line of research on workplace learning by residents and experienced physicians needs to be expanded, as investigating the relationship between organisational practices, experience, learning attitudes and expertise may contribute to efficient practice and highquality health care. In future research, we will assess the degree of deliberate practice in participants' behaviour and link this to measures of expertise. We further suggest observing the learning opportunities in practice, including knowledge sharing practices and supervision, and implementing and testing the proposed interventions to focus efforts on learning. Detailed diary studies of excellent clinicians may shed light on the individual practices contributing to expertise (Ericsson 2004).

Acknowledgments We would like to thank Jeroen Kooman, Richard Koopmans, Walter van Mook, Roger Rennenberg and Coen Stehouwer of the department of Internal Medicine at Maastricht University Medical Center for their support in developing the materials for this study and reflecting on the outcomes. We would also like to thank the residents and internists who participated in this study.

Open Access This article is distributed under the terms of the Creative Commons Attribution Noncommercial License which permits any noncommercial use, distribution, and reproduction in any medium, provided the original author(s) and source are credited.

\section{References}

American Medical Association. (2009). Code of medical ethics: Current opinions with annotations, 20082009. Summary retrieved February 14, 2010, from the AMA website: http://www.ama-assn.org/ ama/pub/physician-resources/medical-ethics/code-medical-ethics/principles-medical-ethics.shtml.

Bleakley, A. (2006). Broadening conceptions of learning in medical education: the message from teamworking. Medical Education, 40(2), 150-157.

Davis, D. (2009). How to help professionals maintain and improve their knowledge and skills: Triangulating best practices in medicine. In K. A. Ericsson (Ed.), Development of professional expertise: Toward measurement of expert performance and design of optimal learning environments (pp. 180-202). New York, NY: Cambridge University Press.

Deketelaere, A., Kelchtermans, G., Struyf, E., \& De Leyn, P. (2006). Disentangling clinical learning experiences: an exploratory study on the dynamic tensions in internship. Medical Education, 40(9), 908-915.

Dornan, T., Boshuizen, H., King, N., \& Scherpbier, A. (2007). Experience-based learning: a model linking the processes and outcomes of medical students' workplace learning. Medical Education, 41(1), 84-91.

Duffy, F. D. (2008). Commentary: training internists for practice focused on meeting patient needs. Academic Medicine, 83(10), 893-896.

Dunn, T. G., \& Shriner, C. (1999). Deliberate practice in teaching: What teachers do for self-improvement. Teaching and Teacher Education, 15(6), 631-651.

Edmondson, A. (1999). Psychological safety and learning behavior in work teams. Administrative Science Quarterly, 44(2), 350-383.

Emans, B. (2004). Interviewing: Theory, techniques and training. Groningen, The Netherlands: WoltersNoordhoff.

Epstein, R. M., Siegel, D. J., \& Silberman, J. (2008). Self-monitoring in clinical practice: A challenge for medical educators. Journal of Continuing Education in the Health Professions, 28(1), 5-13.

Eraut, M. (2000). Non-formal learning and tacit knowledge in professional work. British Journal of Educational Psychology, 70, 113-136.

Eraut, M. (2004). Informal learning in the workplace. Studies in Continuing Education, 26(2), 247-273.

Eraut, M. (2007). Learning from other people in the workplace. Oxford Review of Education, 33(4), $403-422$.

Ericsson, K. A. (2004). Deliberate practice and the acquisition and maintenance of expert performance in medicine and related domains. Academic Medicine, 79(10 Suppl), S70-S81. 
Ericsson, K. A. (2006). The Influence of experience and deliberate practice on the development of superior expert performance. In K. A. Ericsson, N. Charness, P. J. Feltovich, \& R. R. Hoffman (Eds.), The Cambridge handbook of expertise and expert performance (pp. 683-704). New York, NY: Cambridge University Press.

Ericsson, K. A., Krampe, R. T., \& Tesch-Römer, C. (1993). The role of deliberate practice in the acquisition of expert performance. Psychological Review, 100(3), 363-406.

Eva, K. W., \& Regehr, G. (2005). Self-assessment in the health professions: A reformulation and research agenda. Academic Medicine, 80(10), S46-S54.

Eva, K. W., \& Regehr, G. (2008). I'll never play professional football and other fallacies of self-assessment. Journal of Continuing Education in the Health Professions, 28(1), 14-19.

Frank, J. R. (2005). The CanMEDS 2005 physician competency framework. Ottawa, Ontario: The Royal College of Physicians and Surgeons of Canada.

General Medical Council UK. (2009). Good medical practice. Retrieved February 14, 2010, from the GMC UK website: http://www.gmc-uk.org/guidance/good_medical_practice/duties_of_a_doctor.asp.

Guest, C. B., Regehr, G., \& Tiberius, R. G. (2001). The life long challenge of expertise. Medical Education, 35(1), 78-81.

Hoffman, K. G., \& Donaldson, J. F. (2004). Contextual tensions of the clinical environment and their influence on teaching and learning. Medical Education, 38(4), 448-454.

Holmboe, E. S., Bowen, J. L., Green, M., Gregg, J., DiFrancesco, L., Reynolds, E., et al. (2005). Reforming internal medicine residency training. A report from the society of general internal medicine's task force for residency reform. Journal of General Internal Medicine, 20(12), 1165-1172.

Kisiel, J. B., Bundrick, J. B., \& Beckman, T. J. (2010). Resident physicians' perspectives on effective outpatient teaching: A qualitative study. Advances in Health Sciences Education (in press). doi: 10.1007/s10459-009-9202-2.

Mamede, S., \& Schmidt, H. G. (2004). The structure of reflective practice in medicine. Medical Education, 38(12), 1302-1308.

Mann, K., Gordon, J., \& MacLeod, A. (2009). Reflection and reflective practice in health professions education: a systematic review. Advances in Health Sciences Education, 14, 595-621. doi: 10.1007/s10459-007-9090-2.

Mylopoulos, M., \& Regehr, G. (2007). Cognitive metaphors of expertise and knowledge: Prospects and limitations for medical education. Medical Education, 41(12), 1159-1165.

Neuendorf, K. A. (2002). The content analysis guidebook. Thousand Oaks, CA: Sage.

Norman, G. R., Eva, K., Brooks, L., \& Hamstra, S. (2006). Expertise in medicine and surgery. In K. A. Ericsson, N. Charness, P. J. Feltovich, \& R. R. Hoffman (Eds.), The cambridge handbook of expertise and expert performance (pp. 339-354). New York, NY: Cambridge University Press.

Pintrich, P. R. (2000). The role of goal orientation in self-regulated learning. In M. Boekaerts \& P. R. Pintrich (Eds.), Handbook of self regulation (pp. 451-502). San Diego, CA, US: Academic Press.

Royal Dutch Medical Association (KNMG). (2003). Gedragsregels en richtlijnen [Rules of conduct and guidelines]. Retrieved March 16, 2010, from the KNMG website: http://knmg.artsennet.nl/dossiers/ Dossiers-op-thema/arts-en-recht-1/Gedragsregels-en-richtlijnen.htm.

Sargeant, J., Mann, K., Sinclair, D., Ferrier, S., Muirhead, P., van der Vleuten, C., et al. (2006). Learning in practice: Experiences and perceptions of high-scoring physicians. Academic Medicine, 81(7), 655-660.

Sheehan, D., Wilkinson, T. J., \& Billett, S. (2005). Interns' participation and learning in clinical environments in a New Zealand hospital. Academic Medicine, 80(3), 302-308.

Slotnick, H. B. (1996). How doctors learn: The role of clinical problems across the medical schoolto-practice continuum. Academic Medicine, 71(1), 28-34.

Slotnick, H. B. (1999). How doctors learn: Physicians' self-directed learning episodes. Academic Medicine, 74(10), 1106-1117.

Sonnentag, S., \& Kleine, B. M. (2000). Deliberate practice at work: A study with insurance agents. Journal of Occupational and Organizational Psychology, 73(1), 87-102.

Stok-Koch, L., Bolhuis, S., \& Koopmans, R. (2007). Identifying factors that influence workplace learning in postgraduate medical education. Education for Health, 20(1), 1-8.

Sutkin, G., Wagner, E., Harris, I., \& Schiffer, R. (2008). What makes a good clinical teacher in medicine? A review of the literature. Academic Medicine, 83(5), 452-466.

Teunissen, P. W., Scheele, F., Scherpbier, A. J. J. A., van der Vleuten, C. P. M., Boor, K., van Luijk, S. J., et al. (2007). How residents learn: Qualitative evidence for the pivotal role of clinical activities. Medical Education, 41(8), 763-770.

Van de Wiel, M. W. J., Szegedi, K. H. P., \& Weggeman, M. C. D. P. (2004). Professional learning: Deliberate attempts at developing expertise. In H. P. A. Boshuizen, R. Bromme, \& H. Gruber (Eds.), 
Professional learning: Gaps and transitions on the way from novice to expert (pp. 181-206). Dordrecht: Kluwer.

Van den Bossche, P., Gijselaers, W. H., Segers, M., \& Kirschner, P. A. (2006). Social and cognitive factors driving teamwork in collaborative learning environments: Team learning beliefs and behaviors. Small Group Research, 37(5), 490-521.

Wyatt, J. C., \& Sullivan, F. (2005). Keeping up: Learning in the workplace. British Medical Journal, 331(7525), 1129-1132.

Zimmerman, B. J. (2000). Attaining self-regulation: A social cognitive perspective. In M. Boekaerts \& P. R. Pintrich (Eds.), Handbook of self regulation (pp. 13-39). San Diego, CA, US: Academic Press.

Zimmerman, B. J. (2006). Development and adaptation of expertise: The role of self-regulatory processes and beliefs. In K. A. Ericsson, N. Charness, P. J. Feltovich, \& R. R. Hoffman (Eds.), The Cambridge handbook of expertise and expert performance (pp. 705-722). New York, NY, US: Cambridge University Press. 